\title{
Awareness of fertility preservation among Chinese medical students
}

\author{
Elaine YL Ng, Jeffrey KH Ip, Diane R Mak, Andrea YW Chan, Jacqueline PW Chung *
}

\section{A B S T R A C T}

Introduction: The fertility preservation (FP) services offered in Hong Kong are underutilised. There have been no previous studies on Chinese medical students to investigate the underlying reasons for this underutilisation in terms of awareness, knowledge, and attitudes towards FP and age-related fertility.

Methods: This was a cross-sectional survey among Chinese medical students in Hong Kong.

Results: The majority of participants (77.8\%) were not familiar with any clinics or specialists who provide FP services. The vast majority $(88.1 \%)$ underestimated female infertility at age 45 years, and $89.8 \%$ overestimated the age of male fertility decline. The students' FP knowledge was mainly acquired from electronic media (58.4\%) and medical school (57.6\%). Medical students showed overwhelming support towards FP for medical reasons (97.9\%) but had mixed responses about FP for elective reasons related to career development in women (58.8\%). Of the participants, $80.2 \%$ agreed that the government medical reasons.

Conclusion: This study highlights the limited awareness and knowledge of FP among Chinese medical students. There is a strong worldwide need to increase education about and exposure to FP in the medical curriculum and improve medical students' knowledge.

\author{
Hong Kong Med J 2020;26:184-91

https://doi.org/10.12809/hkmj208390 \\ ${ }^{1}$ EYL Ng, BSc \\ 2 JKH Ip \\ 2 DR Mak \\ ${ }^{2}$ AYW Chan \\ ${ }^{1}$ JPW Chung *, MB, ChB (CUHK), FHKAM (Obstetrics and Gynaecology) \\ Department of Obstetrics and Gynaecology, The Chinese University of \\ Hong Kong, Hong Kong \\ Faculty of Medicine, The Chinese University of Hong Kong, Hong Kong
}

* Corresponding author: jacquelinechung@cuhk.edu.hk

New knowledge added by this study

- Chinese medical students tend to overestimate the success rate of in vitro fertilisation and the age of male fertility decline.

- Chinese medical students who had completed the clinical attachments of the obstetrics and gynaecology module rotations showed significantly higher awareness of fertility preservation, reproductive techniques used, and the availability of specialty clinics than did medical students who had not completed the module.

Implications for clinical practice or policy

Appropriate and timely education can improve medical students' awareness and knowledge.

- More involvement from the public sector and enhanced facilities in terms of service provision and financial support could increase FP service utilisation.

\section{Introduction}

Chemotherapy, radiotherapy, certain medications for cancer, and some rheumatological and haematological diseases are gonadotoxic, which can jeopardise patients' fertility, particularly that of young cancer survivors. ${ }^{1}$ With advancements in treatment, the 5-year survival rate of patients with cancer in childhood and adolescence has increased to over $80 \%{ }^{2}$ Thus, improving their quality of life and reducing their risk of infertility is an important aspect of their management plan.

International clinical guidelines, including the American Society of Clinical Oncology (ASCO), ${ }^{3}$ European Society for Medical Oncology (ESMO), ${ }^{4}$ and Royal College of Radiologists guidelines, ${ }^{5}$ suggest discussion of fertility preservation (FP) with patients of childhood and reproductive age during the course of cancer therapy. However, a study showed that fewer than half of oncologists routinely refer their patients to reproductive endocrinologists, and even fewer oncologists follow the guidelines, despite their willingness to discuss infertility in relation to cancer therapy. ${ }^{6}$ Moreover, a lack of awareness and related training about FP among clinicians may cause underutilisation of FP services worldwide, including in Canada, the US, and Hong Kong. ${ }^{7-9}$ In Hong Kong, clinicians and patients alike may consider FP as an expensive, privatised option without subsidisation.

In a previous cross-sectional study that evaluated the awareness, attitudes, and knowledge 
of FP among clinicians across different specialties in Hong Kong, only $45.6 \%$ of clinicians were familiar with FP. ${ }^{10}$ As current medical students will become our future clinicians, it is important to assess their level of understanding and awareness of fertility and FP, as this may greatly influence their future practice and consideration of appropriate interventions to improve affected patients' outcomes. Crosssectional studies have been conducted to assess college students' awareness and knowledge of fertility in Canada, ${ }^{11}$ Serbia, ${ }^{12}$ and the US. ${ }^{13}$ These studies in Western populations showed knowledge inadequacy about age-related fertility decline and FP. However, to the best of our knowledge, there are no studies in a Chinese population that have aimed to investigate the awareness, knowledge gaps, and attitudes of medical students regarding fertility and FP. Therefore, the aims of this study were to evaluate the awareness of, attitudes towards, and knowledge regarding FP among Chinese medical students in Hong Kong.

\section{Methods}

This was a cross-sectional survey conducted from November 2018 to June 2019. The study population consisted of Chinese medical students from The Chinese University of Hong Kong. Chinese undergraduate students aged $\geq 18$ years studying in the Medicine programme and capable of communicating in English were included. Those who were non-Chinese, under age 18 years, incapable of communicating in English, and those who refused to join the study were excluded.

Eligible participants were invited to complete a self-administered online survey. The online survey was sent to participants by internal mass email and social networking applications. Snowball sampling was done by encouraging medical students to send the online survey to their classmates to boost the response rate.

The online survey was developed on an electronic form (MyCUform). The self-administered survey included a brief explanation and was comprised of four parts: (1) baseline demographic data (Table 1); (2) awareness of FP; (3) knowledge about FP (Table 2); multiple choice questions consisting of five or six options on knowledge about fertility and FP; and (4) attitudes towards FP (Tables 3 and 4). It consisted of 38 questions and took approximately 15 minutes to finish. The survey was developed after reviewing the literature. ${ }^{14-16}$ It was assessed for logical validity by three physicians in the Department of Obstetrics and Gynaecology, who reviewed the accuracy of the contents. The survey was also piloted on a small number of doctors and medical students for content clarity and modified accordingly to incorporate the pilot participants'

\section{香港醫學生對保存生殖能力的認知程度}

\section{吳綺莉、葉家謙、麥瑞臻、陳婉穎、鍾佩樺}

引言：在香港, 保存生殖能力服務的使用率不足。本研究旨在評估醫 學生對於保存生殖能力以及對於隨年齡增長而引起生育能力改變的認 知、知識和態度。

方法: 研究採用橫斷面調查, 向醫學生分發自填形式的網上問卷。

結果：絕大多數醫學生 $(77.8 \%)$ 不熟悉為保存生殖能力提供服務的 診所或醫生， $88.1 \%$ 低估了 45 歲女性的不育率， $89.8 \%$ 則高估了年長 男性的生育能力。醫學生對於保存生殖能力的知識主要來自電子媒體 （58.4\%）和醫學院（57.6\%）。醫學生普遍支持基於醫療原因而使用 保存生殖能力服務（97.9\%），但對於女醫學生的事業發展而使用保 存生殖能力服務, 支持率只有 $58.8 \%$ 。高達 $80.2 \%$ 醫學生同意政府應為 有醫療原因需要的病人提供保存生殖能力服務津貼。

結論 : 研究反映了醫學生對保存生殖能力的認知和知識有限, 這亦是 世界各地普遍存在的問題。醫學院應在醫學課程中加入對如何保存生 殖能力的教育和接觸, 提高醫學生對這方面的認知和知識。 feedback. The final version was then administered to the full study's participants.

Statistical analysis was performed using SPSS (Windows version 24.0; IBM Corp, Armonk [NY], US). Continuous data were described as means, standard deviations, and percentiles. Categorical

TABLE I. Demographic data of participants $(n=243) *$

\begin{tabular}{|c|c|}
\hline & No. (\%) \\
\hline Age (years) & $\begin{array}{l}21.59 \pm 1.848 \\
\text { (range, 18-28) }\end{array}$ \\
\hline \multicolumn{2}{|l|}{ Gender } \\
\hline Male & $103(42.4 \%)$ \\
\hline Female & $140(57.6 \%)$ \\
\hline \multicolumn{2}{|l|}{ Current relationship status } \\
\hline Currently in a relationship & $117(48.1 \%)$ \\
\hline Currently not in a relationship & $126(51.9 \%)$ \\
\hline \multicolumn{2}{|l|}{ Religion } \\
\hline Buddhism & $7(2.9 \%)$ \\
\hline Catholic & $17(7.0 \%)$ \\
\hline Christian & $68(28.0 \%)$ \\
\hline Atheist & $24(9.9 \%)$ \\
\hline No & $124(51.0 \%)$ \\
\hline Others & $3(1.2 \%)$ \\
\hline \multicolumn{2}{|l|}{ Year of medical school } \\
\hline Junior (years 1-4) & $114(46.9 \%)$ \\
\hline Senior (years 5-6) & $129(53.1 \%)$ \\
\hline
\end{tabular}

Data are shown as mean \pm standard deviation or No (\%), unless otherwise specified 
TABLE 2. Knowledge about fertility preservation among junior and senior medical students (given 5-9 choices for each question)*

\begin{tabular}{|c|c|c|c|c|}
\hline & $\begin{array}{l}\text { Junior } \\
(n=114)\end{array}$ & $\begin{array}{l}\text { Senior } \\
(n=129)\end{array}$ & $\begin{array}{c}\text { Total } \\
(n=243)\end{array}$ & $P$ value \\
\hline \multicolumn{4}{|c|}{ Age range of women's fertility peak (years) } & 0.304 \\
\hline$<20$ & $6(5.3 \%)$ & $10(7.8 \%)$ & $16(6.6 \%)$ & \\
\hline $20-24$ & $50(43.9 \%)$ & $56(43.4 \%)$ & $106(43.6 \%)$ & \\
\hline $25-29$ & $50(43.9 \%)$ & $60(46.5 \%)$ & $110(45.3 \%)$ & \\
\hline $30-34$ & $5(4.4 \%)$ & $3(2.3 \%)$ & $8(3.3 \%)$ & \\
\hline $40-45$ & $3(2.6 \%)$ & 0 & $3(1.2 \%)$ & \\
\hline \multicolumn{4}{|c|}{$\begin{array}{l}\text { Age range at which women's fertility significantly } \\
\text { decreases (years) }\end{array}$} & 0.429 \\
\hline$<29$ & $4(3.5 \%)$ & $1(0.8 \%)$ & $5(2.1 \%)$ & \\
\hline $30-34$ & $17(14.9 \%)$ & $14(10.9 \%)$ & $31(12.8 \%)$ & \\
\hline 35-39 & $49(43.0 \%)$ & $55(42.6 \%)$ & $104(42.8 \%)$ & \\
\hline $40-44$ & $32(28.1 \%)$ & $41(31.8 \%)$ & $73(30.0 \%)$ & \\
\hline $45-49$ & 12 (10.5\%) & 18 (14.0\%) & 30 (12.3\%) & \\
\hline \multicolumn{4}{|c|}{$\begin{array}{l}\text { Age range at which men's fertility significantly } \\
\text { decreases (years) }\end{array}$} & 0.182 \\
\hline 35-39 & $1(0.9 \%)$ & 3 (2.3\%) & $4(1.6 \%)$ & \\
\hline $40-44$ & 9 (7.9\%) & $12(9.3 \%)$ & $21(8.6 \%)$ & \\
\hline $45-49$ & 12 (10.5\%) & 9 (7.0\%) & 21 (8.6\%) & \\
\hline $50-54$ & $24(21.1 \%)$ & $21(16.3 \%)$ & 45 (18.5\%) & \\
\hline $55-59$ & 16 (14.0\%) & 12 (9.3\%) & 28 (11.5\%) & \\
\hline $60-64$ & 29 (25.4\%) & 26 (20.2\%) & 55 (22.6\%) & \\
\hline $65-69$ & 7 (6.1\%) & 10 (7.8\%) & $17(7.0 \%)$ & \\
\hline$>70$ & 16 (14.0\%) & 36 (27.9\%) & 52 (21.4\%) & \\
\hline
\end{tabular}

Percentage of women who are infertile at age $45 \quad 0.807$ years

\begin{tabular}{|cccc|}
\hline $10 \%$ & $6(5.3 \%)$ & $7(5.4 \%)$ & $13(5.3 \%)$ \\
\hline $30 \%$ & $31(27.2 \%)$ & $30(23.3 \%)$ & $61(25.1 \%)$ \\
\hline $50 \%$ & $36(31.6 \%)$ & $37(28.7 \%)$ & $73(30.0 \%)$ \\
\hline $70 \%$ & $30(26.3 \%)$ & $37(28.7 \%)$ & $67(27.6 \%)$ \\
\hline $90 \%$ & $11(9.6 \%)$ & $18(14.0 \%)$ & $29(11.9 \%)$ \\
\hline
\end{tabular}

If a woman aged 25-30 years and a man regularly $\quad 0.028$ have unprotected intercourse during a period of 1 year, the chance of pregnancy

\begin{tabular}{|lccc|}
\hline $10 \%-19 \%$ & $2(1.8 \%)$ & 0 & $2(0.8 \%)$ \\
\hline $20 \%-29 \%$ & $1(0.9 \%)$ & $2(1.6 \%)$ & $3(1.2 \%)$ \\
\hline $30 \%-39 \%$ & $7(6.1 \%)$ & $4(3.1 \%)$ & $11(4.5 \%)$ \\
\hline $40 \%-49 \%$ & $4(3.5 \%)$ & $1(0.8 \%)$ & $5(2.1 \%)$ \\
\hline $50 \%-59 \%$ & $7(6.1 \%)$ & $7(5.4 \%)$ & $14(5.8 \%)$ \\
$60 \%-69 \%$ & $11(9.6 \%)$ & $12(9.3 \%)$ & $23(9.5 \%)$ \\
$70 \%-79 \%$ & $42(36.8 \%)$ & $34(26.4 \%)$ & $76(31.3 \%)$ \\
\hline $80 \%-89 \%$ & $18(15.8 \%)$ & $46(35.7 \%)$ & $64(26.3 \%)$ \\
$90 \%-100 \%$ & $22(19.3 \%)$ & $23(17.8 \%)$ & $45(18.5 \%)$ \\
\hline * Data are shown as No. (\%). Correct answers are shown in \\
bold
\end{tabular}

TABLE 2. (cont'd)

\begin{tabular}{|c|c|c|c|c|}
\hline & $\begin{array}{l}\text { Junior } \\
(n=114)\end{array}$ & $\begin{array}{l}\text { Senior } \\
(n=129)\end{array}$ & $\begin{array}{c}\text { Total } \\
(n=243)\end{array}$ & $P$ value \\
\hline \multicolumn{4}{|c|}{$\begin{array}{l}\text { The chance a woman will become pregnant if she is } \\
\text { aged } 35-40 \text { years }\end{array}$} & 0.069 \\
\hline $10 \%-19 \%$ & 7 (6.1\%) & $4(3.1 \%)$ & $11(4.5 \%)$ & \\
\hline $20 \%-29 \%$ & $8(7.0 \%)$ & $6(4.7 \%)$ & $14(5.8 \%)$ & \\
\hline $30 \%-39 \%$ & 18 (15.8\%) & 14 (10.9\%) & 32 (13.2\%) & \\
\hline $40 \%-49 \%$ & 19 (16.7\%) & $18(14.0 \%)$ & 37 (15.2\%) & \\
\hline $50 \%-59 \%$ & 30 (26.3\%) & $28(21.7 \%)$ & 58 (23.9\%) & \\
\hline $60 \%-69 \%$ & 17 (14.9\%) & 28 (21.7\%) & 45 (18.5\%) & \\
\hline $70 \%-79 \%$ & 15 (13.2\%) & $21(16.3 \%)$ & $36(14.8 \%)$ & \\
\hline $80 \%-89 \%$ & 0 & $8(6.2 \%)$ & 8 (3.3\%) & \\
\hline $90 \%-100 \%$ & 0 & $2(1.6 \%)$ & $2(0.8 \%)$ & \\
\hline \multicolumn{4}{|c|}{$\begin{array}{l}\text { The average chance of having a child among } \\
\text { couples that undergo treatment with in vitro } \\
\text { fertilisation }\end{array}$} & $<0.0001$ \\
\hline $10 \%-19 \%$ & 7 (6.1\%) & $9(7.0 \%)$ & 16 (6.6\%) & \\
\hline $20 \%-29 \%$ & $6(5.3 \%)$ & $11(8.5 \%)$ & 17 (7.0\%) & \\
\hline $30 \%-39 \%$ & 13 (11.4\%) & 44 (34.1\%) & 57 (23.5\%) & \\
\hline $40 \%-49 \%$ & 17 (14.9\%) & 18 (14.0\%) & 35 (14.4\%) & \\
\hline $50 \%-59 \%$ & $20(17.5 \%)$ & $21(16.3 \%)$ & $41(16.9 \%)$ & \\
\hline $60 \%-69 \%$ & $10(8.8 \%)$ & 11 (8.5\%) & 21 (8.6\%) & \\
\hline $70 \%-79 \%$ & $25(21.9 \%)$ & $9(7.0 \%)$ & $34(14.0 \%)$ & \\
\hline $80 \%-89 \%$ & 12 (10.5\%) & $3(2.3 \%)$ & 15 (6.2\%) & \\
\hline $90 \%-100 \%$ & $4(3.5 \%)$ & $3(2.3 \%)$ & 7 (2.9\%) & \\
\hline
\end{tabular}

data were summarised as frequencies and percentiles. Subgroup analyses were performed between gender and year groups, with the medical students split into junior (year 1-4) and senior (year 5-6) year groups. Junior medical students had not completed the clinical attachments of the obstetrics and gynaecology module rotation (OB-GYN), whereas senior medical students had finished the OB-GYN module in year 5 . The categorical data were tested by Pearson's Chi squared test or Fisher's exact test to check for significant differences between groups. Results with P values of $<0.05$ were considered statistically significant.

\section{Results}

Approximately 700 Chinese medical students were approached through social networking applications and email, and 243 completed the online survey (response rate: $34.7 \%$ ). Table 1 summarises the participants' demographic data. In terms of age distribution, there was no significant difference $(\mathrm{P}=0.597)$ between the two groups. 


\section{Awareness}

Overall, $71.2 \%(n=173)$ of respondents were aware of FP strategies. Despite this, $77.8 \%(n=189)$ of respondents were not familiar with any clinics or specialists who provide FP services. Senior students showed better awareness than junior students of the above items $(\mathrm{P}<0.001)$. The majority $(86.8 \%$, $\mathrm{n}=211$ ) had not heard of any regulations related to FP. Gamete and embryo freezing were the most well-known FP methods, with female students being significantly more aware than male students of those methods $(\mathrm{P}<0.003)$.

The majority $(71.2 \%, \mathrm{n}=173)$ responded that they would discuss the option of FP with their patients as future doctors, even if the treatment had a $<30 \%$ chance of causing infertility. If a treatment had $\mathrm{a} \geq 70 \%$ chance of causing infertility, nearly all $(95.5 \%, \mathrm{n}=232)$ students would discuss FP.

\section{Knowledge}

Table 2 shows the results of the questions that address knowledge about fertility and FP. Overall, there were no gender differences besides the response regarding the age range of a woman's significant fertility decline: proportionally more female students answered that item correctly $(45.7 \%$ vs $38.8 \%$; $<<0.05)$.

Knowledge regarding FP was mainly acquired from electronic media $(58.4 \%, n=142)$, medical school (57.6\%, $\mathrm{n}=140$ ), and medical professionals (38.7\%, $\mathrm{n}=94)$. More senior students than junior students acquired fertility knowledge through medical school education $(81.4 \%$ vs $30.7 \% ; \mathrm{P}<0.0001)$ and medical professionals $(54.3 \%$ vs $21.1 \%$; $\mathrm{P}<0.0001)$.

Most of the responding students $(86.4 \%$, $\mathrm{n}=210$ ) wished to know more about FP, with $80.7 \%$ $(n=196)$ of the students agreeing that there is a need to incorporate FP material into the medical curriculum.

\section{Attitudes}

Regarding attitudes, $94.2 \% \quad(\mathrm{n}=229)$ of medical students agreed that establishing one or two dedicated clinics or centres for FP counselling is necessary. Subgroup analysis indicated that more male medical students would like to have two dedicated centres $(75.0 \%$ vs $68.2 \%, \mathrm{P}=0.021)$. More senior than junior students agreed that FP should be available solely as a public service $(89.1 \%$ vs $71.9 \%$; $\mathrm{P}=0.001)$. Overall, $97.9 \% \quad(\mathrm{n}=238)$ of participants thought that practice guidelines for FP should be required. More than half of respondents (59.7\%, $\mathrm{n}=145$ ) agreed that there should be an age limit for FP. More female than male students agreed to set an age limit for $\mathrm{FP}(65.7 \%$ vs $51.5 \%, \mathrm{P}=0.025)$.

Among various factors considered by medical students to determine whether to recommend FP to patients, the desire to have children $(51.0 \%$,
TABLE 3. Attitudes towards elective freezing among junior and senior medical students*

Junior $(n=114) \quad$ Senior $(n=129) \quad$ Total $(n=243) \quad P$ value

In general, do you agree that fertility preservation should be provided for the following reasons?

a) Delayed family planning because of cancer treatment 0.754
Yes $112(98.2 \%)$ $126(97.7 \%)$ $238(97.9 \%)$
No
$2(1.8 \%)$
$3(2.3 \%)$
$5(2.1 \%)$

b) Delayed family planning because of career development in women

$\begin{array}{llll}\text { Yes } & 65(57.0 \%) & 78(60.5 \%) & 143(58.8 \%) \\ \text { No } & 49(43.0 \%) & 51(39.5 \%) & 100(41.2 \%)\end{array}$

c) Delayed family planning because of career development in men 0.566
Yes
59 (51.8\%)
$62(48.1 \%)$
$121(49.8 \%)$
No $\quad 55(48.2 \%)$
$67(51.9 \%)$
$122(50.2 \%)$

d) Single women who want to freeze their eggs when they are young, before they find a partner

$\begin{array}{llll}\text { Yes } & 66(57.9 \%) & 66(51.2 \%) & 132(54.3 \%) \\ \text { No } & 48(42.1 \%) & 63(48.8 \%) & 111(45.7 \%)\end{array}$

e) Single men who want to freeze their sperm when they are young, before they find a partner

$\begin{array}{llll}\text { Yes } & 54(47.4 \%) & 47(36.4 \%) & 101(41.6 \%) \\ \text { No } & 60(52.6 \%) & 82(63.6 \%) & 142(58.4 \%)\end{array}$

f) Individuals who may have exposure to occupational hazards like radiation/chemical exposure

$\begin{array}{lccc}\text { Yes } & 109(95.6 \%) & 111(86.0 \%) & 220(90.5 \%) \\ \text { No } & 5(4.4 \%) & 18(14.0 \%) & 23(9.5 \%)\end{array}$

g) Men with poor semen quality who wants to have sperm frozen for future use

$\begin{array}{lrrr}\text { Yes } & 96(84.2 \%) & 105(81.4 \%) & 201(82.7 \%) \\ \text { No } & 18(15.8 \%) & 24(18.6 \%) & 42(17.3 \%)\end{array}$

h) Couples who want to have embryos frozen for future use when it is time for a second child

$\begin{array}{llll}\text { Yes } & 49(43.0 \%) & 59(45.7 \%) & 108(44.4 \%) \\ \text { No } & 65(57.0 \%) & 70(54.3 \%) & 135(55.6 \%)\end{array}$

Imagine if you were a female medical student. Would you consider egg freezing: a) If you had no suitable partner yet?

$\begin{array}{lllr}\text { Yes } & 41(36.0 \%) & 54(41.9 \%) & 95(39.1 \%) \\ \text { No } & 73(64.0 \%) & 75(58.1 \%) & 148(60.9 \%)\end{array}$

b) To focus on your career and postpone family planning?

0.604

$\begin{array}{llll}\text { Yes } & 63(55.3 \%) & 67(51.9 \%) & 130(53.5 \%) \\ \text { No } & 51(44.7 \%) & 62(48.1 \%) & 113(46.5 \%)\end{array}$

Imagine if you were a male medical student. Would you consider sperm freezing: a) If you had no suitable partner yet?

0.380

$\begin{array}{lllr}\text { Yes } & 34(29.8 \%) & 32(24.8 \%) & 66(27.2 \%) \\ \text { No } & 80(70.2 \%) & 97(75.2 \%) & 177(72.8 \%)\end{array}$

b) To focus on your career and postpone family planning?

$\begin{array}{lllr}\text { Yes } & 34(29.8 \%) & 43(33.3 \%) & 77(31.7 \%) \\ \text { No } & 80(70.2 \%) & 86(66.7 \%) & 166(68.3 \%)\end{array}$

* Data are shown as No. (\%) 
TABLE 4. Attitudes towards family planning among junior and senior medical students*

\begin{tabular}{|c|c|c|c|c|}
\hline & Junior $(n=114)$ & Senior $(n=129)$ & Total $(n=243)$ & $P$ value \\
\hline \multicolumn{4}{|l|}{ How important is your future fertility to you? } & 0.268 \\
\hline Not important & $19(16.7 \%)$ & $15(11.6 \%)$ & $34(14.0 \%)$ & \\
\hline Somewhat important & $56(49.1 \%)$ & $58(45.0 \%)$ & $114(46.9 \%)$ & \\
\hline Very important & $39(34.2 \%)$ & $56(43.4 \%)$ & $95(39.1 \%)$ & \\
\hline \multicolumn{4}{|c|}{ At what age do you plan to have your first child? (years) } & 0.337 \\
\hline$<29$ & $28(24.6 \%)$ & $23(17.8 \%)$ & $51(21.0 \%)$ & \\
\hline $30-34$ & $41(36.0 \%)$ & $63(48.8 \%)$ & $104(42.8 \%)$ & \\
\hline $35-39$ & $4(3.5 \%)$ & $3(2.3 \%)$ & $7(2.9 \%)$ & \\
\hline $40-44$ & 0 & $1(0.8 \%)$ & $1(0.4 \%)$ & \\
\hline Not interested in having children at all & $17(14.9 \%)$ & $14(10.9 \%)$ & $31(12.8 \%)$ & \\
\hline I haven't really thought about that & $24(21.1 \%)$ & $25(19.4 \%)$ & $49(20.2 \%)$ & \\
\hline \multicolumn{5}{|c|}{ Will you delay family planning for the following reasons? (can choose more than one) } \\
\hline Career building & $61(53.5 \%)$ & $82(63.6 \%)$ & $143(58.8 \%)$ & 0.112 \\
\hline Wanting financial security & $61(53.5 \%)$ & $71(55.0 \%)$ & $132(54.3 \%)$ & 0.811 \\
\hline Not having a partner & $71(62.3 \%)$ & $80(62.0 \%)$ & $151(62.1 \%)$ & 0.966 \\
\hline Not interested in having children & $30(26.3 \%)$ & $32(24.8 \%)$ & $62(25.5 \%)$ & 0.788 \\
\hline No, I will not delay family planning & $14(12.3 \%)$ & $14(10.9 \%)$ & $28(11.5 \%)$ & 0.728 \\
\hline
\end{tabular}

* Data are shown as No. (\%)

$\mathrm{n}=124)$, the prognosis of cancer or a medical condition $(23.5 \%, \mathrm{n}=57)$, and time available before gonadotoxic treatment $(7.4 \%, \mathrm{n}=18)$ were the most likely considerations.

Most participants $(80.2 \%, \mathrm{n}=195)$ responded that the government should subsidise FP in patients undergoing gonadotoxic treatment, with senior students expressing stronger support for subsidisation than junior students $(86.0 \%$ vs $73.7 \%$; $\mathrm{P}<0.02)$. More than half of the responding students agreed that the government should subsidise $30 \%$ to $50 \%$ of the cost of FP procedures including sperm (79.8\%, $\mathrm{n}=194)$ and egg freezing $(80.2 \%, \mathrm{n}=195)$, and in vitro fertilisation (IVF) [67.9\%, $n=165]$. More senior than junior students thought that the government should subsidise $>70 \%$ of the cost of IVF (34.1\% vs $20.1 \%$; $\mathrm{P}<0.02$ ).

Table 3 shows the respondents' attitudes towards elective and medical gamete and embryo freezing. More male students than female students expressed agreement with FP provision to men because of having no suitable partner $(34.0 \%$ vs 22.1\%; $\mathrm{P}<0.05)$. Table 4 illustrates attitudes towards family planning among the responding medical students. More male than female students were determined not to delay their family planning $(16.5 \%$ vs $7.9 \%, \mathrm{P}=0.037$ ).

\section{Discussion}

With the advancement of technology, FP has become increasingly effective at enabling patients who have undergone gonadotoxic treatment to raise families. However, as shown by many previous studies on medical students' understanding of FP, this study reflects an overall worldwide tendency towards a lack of awareness and knowledge about fertility and FP. ${ }^{11-13}$ To the best of our knowledge, this is the first study that has aimed to investigate the awareness, knowledge, and attitudes of Chinese medical students regarding fertility and FP, as well as identifying their knowledge gaps in the subject.

\section{Awareness}

The majority of Chinese medical students in Hong Kong have heard of at least one FP strategy. Senior students had significantly greater awareness than junior students of FP, reproductive techniques, and the availability of specialty clinics, likely reflecting the knowledge and exposure gained during the clinical OB-GYN module in the fifth year of study. This suggests that appropriate and timely education can improve medical students' awareness of FP.

Previous studies have shown that even brief educational interventions about FP to medical students and house staff have potential benefits. ${ }^{13}$ To provide quality service, ASCO and ESMO guidelines suggest that patients with cancer be informed of their potential fertility decline and referred to FP services after treatment. ${ }^{3,4}$ Most students responded that they would refer patients to FP services even if treatment had only a low risk of infertility, but they were not familiar with the actual practice of FP, 
including relevant regulations and referral methods. Downloadable fact sheets on the effects of cancer treatment on fertility, available options for FP, and a list of service providers with reference costs stated should be available and accessible for proper patient education and counselling.

\section{Knowledge}

There are several misconceptions among medical students regarding knowledge about fertility and FP. The responding medical students tended to overestimate the age of the female fertility peak and the success rate of IVF and underestimate the risk of infertility in women at age 45 years (Table 2). Overestimation of female fertility has also been observed in overseas studies..$^{11-13,17,18}$ Medical students have better knowledge about female fertility than male fertility. This could be explained by the fact that there have been many more studies about the concern of female fertility decline with age. As sex education programmes at the secondary and university levels mainly emphasise pregnancy prevention education rather than infertility awareness, there may be a lack of knowledge about the impact of ageing on fertility among women. ${ }^{11}$ Fertility-related knowledge should be included in the undergraduate medical curriculum and ideally be integrated in high school education as well to enhance public education on this topic. Beyond patient care, medical students' inadequate knowledge about this topic also has great implications for their future careers and personal lives. They may delay their own family planning for career reasons without sufficient consideration of their impending fertility decline or may have a false sense of security regarding the success rate of IVF. Therefore, more education about fertility is required, which was also supported by the respondents of our study.

Electronic media play a significant role in the promotion of FP, especially among junior students. In contrast, medical school was the main source of FP knowledge for senior students, followed by medical professionals and electronic media. This is consistent with findings in American medical students and house staff. ${ }^{13}$ Media reports of female celebrities undergoing FP procedures, particularly egg freezing, could explain the high prevalence of student familiarity with this procedure and their lack of knowledge about other, less popular options. ${ }^{19}$ Knowledge acquisition through both the medical curriculum and electronic media have proven to be significant, particularly in people who have not received formal education about FP. This can be applied to the general public, although it poses a risk of promoting misinformation: people could be misled into having a false sense of security regarding successful childbearing late in one's reproductive life through the use of FP methods. ${ }^{11}$ Therefore, caution should be used to ensure that materials released through the media are accurate.

\section{Attitudes}

Most of the responding medical students would first consider the patient's desire when referring patients for FP, while $41.3 \%$ of physicians would consider the patient's prognosis first. ${ }^{10}$ This finding could be explained by the medical students' lack of medical practice experience and doctors' awareness of resource limitations, as it has been shown that junior doctors make judgements mostly based on their own assumptions, compared with the experience-based judgements made by senior doctors. ${ }^{20}$

The private sector is the only current provider of FP services in Hong Kong. More male than female medical students who responded to our survey had positive attitudes towards the establishment of related facilities. The cost of freezing gametes is at least US\$7800 (US\$1 to HK\$7.8), ${ }^{21}$ and the median monthly household income of a 1-person family in Hong Kong is US\$1282. ${ }^{22}$ There are currently no gamete freezing subsidy programmes available. Such high costs are unaffordable to many patients, and especially patients with cancer are already financially burdened by their current treatment. In this regard, most medical students agreed that the government should subsidise FP services to patients undergoing gonadotoxic treatment, with more than half agreeing that $30 \%$ to $50 \%$ is a reasonable subsidy proportion.

There has been an increasing trend towards elective FP in recent years, which has opened up a debate about the ethicality of FP for nonmedical indications and whether FP should only be provided for medical reasons. Our study reflected overwhelming support for FP for medical reasons. However, the responding medical students' opinions were mixed regarding elective freezing for nonmedical indications. Only approximately half of the respondents agreed that FP should be provided to people because they have not found a suitable partner, or because they delay family planning for the sake of career development. Despite the mixed responses regarding elective freezing, Chinese medical students from Hong Kong were more supportive of elective freezing than undergraduates and medical students from the US. ${ }^{23}$ This finding may be driven by the higher cost of FP in the US compared with that in Hong Kong. ${ }^{23}$ Indeed, elective freezing has gained popularity in recent years. Still, the greater acceptance of FP for medical reasons echoes the healthcare-related perceptions and expectations of patients in Hong Kong: fertility is not a necessity, and FP healthcare is considered a luxury as opposed to a necessity for immediate physical well-being.

This study's participants were more supportive of elective freezing for women than men. This is likely because of their awareness that women's 
fertility declines relatively earlier than that of men. Moreover, women in Hong Kong are expected to have a predominantly domestic and childrearing role within their families, ${ }^{16}$ largely because of deeply rooted traditional Chinese familial constructs in which women tend to take on homemaking roles. However, the male medical students who responded were also concerned about their own family planning. This study's results show that more male than female medical students were determined not to delay their family planning or stated their intent to have gametes frozen because they had no suitable partner.

Most medical students agree that their future fertility is important to them. Over half of the responding medical students stated their intent to delay family planning for career development, and the majority plan to have their first child between age 30 and 34 years (the average age of residency completion is 29 years). However, few responded that they would consider undergoing FP treatments. This paradoxical response is consistent with the results of another study on Hong Kong university students that showed low inclination to seek help in the event of fertility problems compared with Western counterparts. ${ }^{16}$ The taboo of childlessness in Chinese culture may be another reason why planning and conversation are discouraged in the event of infertility. ${ }^{16}$ Thus, students may view FP techniques as drastic and unconventional, preferring natural conception. As discussed earlier, the lack of correct knowledge about age-related female fertility decline could also lead to such results. Medical training is long, potentially delaying doctors from starting families during their most fertile years. Education is beneficial not only to future patients, but also to current and future physicians' quality of life.

\section{Limitations}

As a form of convenience sampling, the online survey method was chosen to efficiently distribute the survey throughout the large population of medical students. However, this inherently came with limitations, including low response rate, small sample size, selection bias, and the inability to characterise non-respondents. Ideally, students of other medical schools in Hong Kong should be included to make our study more comprehensive; however, this would be logistically difficult. Because of constraints on advertising, the study consisted of slightly more senior than junior students and more female than male respondents. Moreover, our study did not specifically ask about the educational background of students that may have influenced their knowledge. However, there was no significant difference in the age distribution between the junior and senior student groups. Information bias may have also affected the responses from students who had not completed the OB-GYN module.

\section{Conclusion}

In conclusion, this study revealed important aspects of FP from the perspective of Chinese medical students in Hong Kong. In particular, we highlighted that awareness and knowledge of FP are limited among medical students. There is a strong worldwide need to increase education about and exposure of FP in the curriculum to improve medical students' knowledge. More involvement from the public sector and enhancement of facilities in terms of service provision and financial support for FP services are also needed. Given the variety of perspectives on childbearing among different cultures, this should be taken into account when doctors consider FP options for their patients and themselves. Only by increasing awareness and knowledge can more accepting attitudes towards FP arise among our doctors, allowing for better clinical outcomes and quality of life for future patients.

\section{Author contributions}

Concept or design: JPW Chung, EYL Ng.

Acquisition of data: All authors.

Analysis or interpretation of data: EYL Ng.

Drafting of the article: All authors.

Critical revision for important intellectual content: JPW Chung.

All authors had full access to the data, contributed to the study, approved the final version for publication, and take responsibility for its accuracy and integrity.

\section{Conflicts of interest}

As an editor of the journal, JPW Chung was not involved in the peer review process of the article. Other authors have no conflicts of interest to disclose.

\section{Acknowledgement}

The authors would like to thank the medical students at The Chinese University of Hong Kong for their kind participation in the study.

\section{Funding/support}

This research received no specific grant from any funding agency in the public, commercial, or not-for-profit sectors.

\section{Ethics approval}

Ethical approval for the study was obtained from the Survey and Behavioural Research Ethics Committee (Ref SBRE-18168).

\section{References}

1. Husson O, Huijgens PC, van der Graaf WTA. Psychosocial challenges and health-related quality of life of adolescents and young adults with hematologic malignancies. Blood 2018;132:385-92. 
2. Siegel RL, Miller KD, Jemal A. Cancer statistics, 2019. CA Cancer J Clin 2019;69:7-34.

3. Oktay K, Harvey $\mathrm{BE}$, Partridge $\mathrm{AH}$, et al. Fertility preservation in patients with cancer: ASCO clinical practice guideline update. J Clin Oncol 2018;36:1994-2001.

4. Peccatori FA, Azim HA Jr, Orecchia R, et al. Cancer, pregnancy and fertility: ESMO Clinical Practice Guidelines for diagnosis, treatment and follow-up. Ann Oncol 2013;24 Suppl 6:vi160-70.

5. The Royal College of Physicians, The Royal College of Radiologists, The Royal College of Obstetrics and Gynaecology. The effects of cancer treatment on reproductive functions: guidance on management 2007. Available from: https://www.rcr.ac.uk/system/files/ publication/field_publication_files/Cancer_fertility_ effects_Jan08.pdf. Accessed 3 Jan 2020.

6. Köhler TS, Kondapalli LA, Shah A, Chan S, Woodruff TK, Brannigan RE. Results from the Survey for Preservation of Adolescent Reproduction (SPARE) study: gender disparity in delivery of fertility preservation message to adolescents with cancer. J Assist Reprod Genet 2011;28:269-77.

7. Chung JP, Haines CJ, Kong GW. Sperm cryopreservation for Chinese male cancer patients: a 17-year retrospective analysis in an assisted reproductive unit in Hong Kong. Hong Kong Med J 2013;19:525-30.

8. Flink DM, Sheeder J, Kondapalli LA. A review of the oncology patient's challenges for utilizing fertility preservation services. J Adolesc Young Adult Oncol 2017;6:31-44.

9. Liu SS, Chan KY, Leung RC, et al. Prevalence and risk factors of human papillomavirus (HPV) infection in Southern Chinese women-a population-based study. PLoS One 2011;6:1-7.

10. Chung JP, Lao TT, Li TC. Evaluation of the awareness of, attitude to, and knowledge about fertility preservation in cancer patients among clinical practitioners in Hong Kong. Hong Kong Med J 2017;23:556-61.

11. Bretherick KL, Fairbrother N, Avila L, Harbord SH, Robinson WP. Fertility and aging: do reproductive-aged Canadian women know what they need to know? Fertil Steril 2010;93:2162-8.

12. Vujčić I, Radičević T, Dubljanin E, Maksimović N, Grujičić S. Serbian medical students' fertility awareness and attitudes towards future parenthood. Eur J Contracept Reprod Health Care 2017;22:291-7.

13. Anspach Will E, Maslow BS, Kaye L, Nulsen J. Increasing awareness of age-related fertility and elective fertility preservation among medical students and house staff: a pre- and post-intervention analysis. Fertil Steril 2017;107:1200-5.e1.

14. Hickman LC, Fortin C, Goodman L, Liu X, Flyckt R. Fertility and fertility preservation: knowledge, awareness and attitudes of female graduate students. Eur J Contracept Reprod Health Care 2018;23:130-8.

15. Schwartz D, Mayaux MJ, Spira A, et al. Semen characteristics as a function of age in 833 fertile men. Fertil Steril 1983;39:530-5.

16. Chan $\mathrm{CH}$, Chan $\mathrm{TH}$, Peterson BD, Lampic C, Tam MY. Intentions and attitudes towards parenthood and fertility awareness among Chinese university students in Hong Kong: a comparison with Western samples. Hum Reprod 2015;30:364-72.

17. Virtala A, Vilska S, Huttunen T, Kunttu K. Childbearing, the desire to have children, and awareness about the impact of age on female fertility among Finnish university students. Eur J Contracept Reprod Health Care 2011;16:108-15.

18. $\mathrm{Yu} \mathrm{L}$, Peterson B, Inhorn MC, Boehm JK, Patrizio P. Knowledge, attitudes, and intentions toward fertility awareness and oocyte cryopreservation among obstetrics and gynecology resident physicians. Hum Reprod 2016;31:403-11.

19. Moss R. Egg freezing is the fastest growing fertility treatment-here's what you need to know. 2019. Available from: https://www.huffingtonpost.co.uk/ entry/egg-freezing-is-the-fastest-growing-fertilitytreatment-heres-what-you-need-to-know-about-it_ uk_5cd1b93ae4b04e275d50f3e0. Accessed 3 Jan 2020.

20. Nilsson MS, Pilhammar E. Professional approaches in clinical judgements among senior and junior doctors: implications for medical education. BMC Med Educ 2009;9:25.

21. Healthy Matters. Your Complete guide to egg freezing in Hong Kong. Jun 2019. Available from: https://www. healthymatters.com.hk/guide-egg-freezing-hong-kongwomen-need-know-preserving-fertility/. Accessed 3 Jan 2020.

22. Census and Statistics Department, Hong Kong SAR Government. Table E032: domestic households by household size and monthly household income (excluding foreign domestic helpers) [Table 9.4A in Quarterly Report on General Household Survey]. Population estimates. 2019. Available from: https://www.censtatd.gov.hk/hkstat/ sub/sp150.jsp?productCode=D5250036. Accessed 3 Jan 2020.

23. Mahesan A, Mundt S, Smith L, Stadtmauer L. Knowledge and attitudes regarding elective oocyte cryopreservation in medical students and undergraduates. Fertil Steril 2017;108:e109-10. 